\title{
Survey of Apparent Density of Tsetse and other Biting flies in Gimbi district, West Wollega, Western Ethiopia
}

\author{
Geremew Batu ${ }^{1}$, Zelalem Abera ${ }^{2 *}$, Aster Tadesse ${ }^{3}$ and Ayantu Hundera ${ }^{4}$ \\ ${ }^{1}$ West Wollega Livestock and Fisheries Development and Resource office; Gimbi, West Wollega Zone, Oromiya Regional State, Ethiopia \\ ${ }^{2}$ Department of Veterinary Clinical Science and Laboratory Technology, School of Veterinary Medicine, Wollega University, Nekemte, \\ Ethiopia \\ ${ }^{3}$ Bedelle Regional Veterinary Laboratory Center; Bedelle, Oromiya Regional State, Ethiopia
}

${ }^{4}$ East Wollega Livestock and Fisheries Development and Resource office; Nekemte, East Wollega Zone, Oromiya Regional State, Ethiopia

Received: 13 September, 2017; Accepted: 17 October, 2017; Published: 02 Janaury, 2018

*Corresponding author: Zelalem Abera, Department of Veterinary Clinical Science and Laboratory Technology, School of Veterinary Medicine, Wollega University, P.O. Box 395, Nekemte, Ethiopia, E-mail: besha.ab9@gmail.com

\begin{abstract}
A cross-sectional study was carried out from March to May 2014 to determine an apparent density of the tsetse and other biting flies in selected peasant associations (PAs) of Gimbi district. The methods employed during the study were deploying trap for the collection of tsetse and other biting flies. Forty five traps were deployed for $48 \mathrm{hr}$ for collection of tsetse fly. During this entomological survey, a total of 58 tsetse flies, 26 Stomoxys, 33 Tabanus and 2 Haematopota were caught from the three selected PAs during study period. The two major Glossina species captured in the study area were G. m. submorsitans (3.4 \%) and G. tachinoides (96.6 \%) in which relatively higher numbers of G. tachnoides were caught. Majority of collected of tsetse flies were females (1.5\%) in which higher number is Glossina tachnoides as compared to G. m. sub. moristans. About 15 Tabanus and 18 Stomoxys were recorded in Tole PA, without the presence of tsetse flies. The absence of these flies in the area might be due to the time in which the survey was conducted. In Jogir PA, about one (1) G. m. sub moristans (female) and fifty six (56) G tachnoides (45 male and 11 females) were investigated. Totally, about fifty seven (57) tsetse flies were recorded this PA. The fly per trap per day in this PA was 1.9. Different biting flies such as Tabanus (10) and Stomoxys (1) were recorded in this PA. Only a single of female G. m. sub moristans with other biting flies like Tabanus (8), Stomoxys (17) and Heamatopota (2) were observed in Inango Denbeli. The overall apparent density of tsetse flies trapped was 0.965 flies/trap/day and male tsetse flies were foremost in number. Different apparent densities of tsetse flies were recorded in three villages or PAs (0 in Tole, 1.93 in Jogir and 0.03 in Inango Denbeli). Other biting flies caught were Stomoxys (22.2 \%), Haematopota (4.4 \%) and Tabanus (73.3 \%). About 1.9 apparent densities for G. tachnoides and 0.03 densities for G. m. submorsitans were recorded in riverine and savanna vegetation types, respectively. Sexes of the tsetse flies were easily identified by enlarged hypophgeum in the posterior ventral part of the abdomen. However low density of tsetse flies was recorded, these flies are very important in transmitting trypanosomosis and other diseases to the animals in Gimbi district either biologically or mechanically. So, an appropriate tsetse control methods should be warranted to reach tsetse infested area in a sustainable manner to alleviate the problem in the area.
\end{abstract}

Key words: Apparent density; District; Entomology; Gimbi; Trypanosomiasis; Tsetse Flies

\section{Introduction}

Livestock contribute a large proportion of the continent's gross domestic product (GDP) and constitute a major source of foreign currency earning for a number of countries. Livestock production, indeed, contributes to improve food security and poverty alleviation in developing world. However, animal diseases, lack of improved stock, poor food resources and other improved stock, poor food resources and other multifaceted problems limit the potential of livestock [1].

Domestic livestock in Africa are important as a source of protein (milk \& meat) to humans, as a source of animal traction, as a source of income (e.g. hides) and investment (social security) and as a source of manure for enhancing agricultural (crop) production. Tsetse-transmitted trypanosomosis affects 37 subSaharan countries; an estimate of 160 million cattle and 260 million sheep and goats are kept in this area of risk extending over 10 million $\mathrm{km}^{2}$ of land [2].

Sub-Saharan Africa faces multiple ecological, economic and social constraints that limit development $[3,4]$. Ethiopia is chiefly an agricultural country whose economy is largely dependent on crop and livestock production. Besides its direct contribution in terms of Gross Domestic Product and foreign earning, livestock provides virtually all the draught power for cultivation and transportation of agricultural crops and people in rural of the country [5]. 
A major constraint for development of many East African agro-pastoral communities is African animal trypanosomiasis or nagana caused by Trypanosoma spp. and vectored by species of tsetse flies (Glossina spp.), and key questions are how should this constraint be removed or managed, and what are the ecosocial consequences. The traditional view of humans managing ecosystems from the outside has been revised to include humans as integral parts of so-called eco-social systems with the management objective seen as the enhancement of sustainability $[3,4,6]$.

Tsetse (/'si:tsi/, US /'tsi:tsi/ or UK /'tsetsi/), sometimes spelled tzetze and also known as tik-tik flies, are large biting flies that inhabit much of mid continental Africa between the Sahara and the Kalahari Deserts [7]. Tsetse flies in Ethiopia are confined to the Southern and Western regions between longitude $33^{\circ}$ and $38^{\circ} \mathrm{E}$ and latitude $5^{\circ}$ and $12^{\circ} \mathrm{N}$. They infest areas which together amount to $220,000 \mathrm{~km} 2 \mathrm{~s}$. Tsetse infested areas lie in the low lands and also in the river valleys of Abay (Blue Nile), infestation, which currently considered as one of Baro, Akobo, Didessa, Ghibe and Omo [8, 9]. About $15-20 \%$ of the land believed to be suitable for livestock production is affected by one or two species of the tsetse flies [10]. Consequently, new areas are being invaded and settled communities are being continually evicted by the advancing tsetse. These areas include the areas in Upper Didessa Valley, the Northern and Northeastern edges of Lake Abaya in the rift valley, the upper reaches of the Omo-Ghibe and its tributaries.

According to who in this account of his journey through southern Ethiopia mention the 'Gendi-fly' (Tsetse) attacking his transport animals and causing a disease locally called 'Gendi/ Kosa' (Trypanosomosis) from which many animals died [11]. So, the earliest history of trypanosomosis in Ethiopia is in accounts given by explorers and travelers telling of the losses of their transport animals when they had encountered tsetse fly belts. Five species of Glossina (G. m. submoristans, G. pallidipes, G. tachinoides, G. f. fuscipes and G. longipennis) have been recorded in Ethiopia and except G. longipennis, all of them are widespread and significant economic importance [12]. It is prevalent in two main regions of Ethiopia i.e. the Northwest and the Southwest regions. In most low lying areas, especially in the south west are infested with trypanosomosis deter animal production [13]

Tsetse can fly at about $20 \mathrm{~km} / \mathrm{h}$ and they are active for something like 30 minutes each day $[14,15]$. So they could travel up to $10 \mathrm{~km}$ every day. However, they tend to make many short flights every day and these are not all in the same direction. Hence, in practice savannah species such as Glossina morsitans and G. pallidipes move about one kilometer a day and a fly front can advance about 25 kilometers in a year [16]. This movement means that areas cleared of tsetse rapidly become re-invaded from adjacent infested areas. Indeed, in experiments carried out in Zimbabwe in the 1980s, virtually fly in a 4 square kilometer block was killed by aerial spraying in one night within a day; the catches in the block were back to normal because flies had swarmed back into the block from neighboring areas [17].
At the beginning of the 20th century, epidemic vector-borne diseases were among the most important global public health problems $[18,19]$. Trypanosomiasis can be transmitted between the hosts mainly by tsetse flies cyclically, by other biting flies mechanically and by other means of transmission [20, 21]. Currently, National Tsetse and Trypanosomiasis Investigation and Control Center (NTTICC) is working on updating tsetse and trypanosomiasis distribution map in Ethiopia, thus wide range of tsetse and trypanosomiasis survey were carried out in Abay or Didessa river system [9]. Mixed livestock and crop productions characterize the predominant farming system in the highlands. With livestock playing a vital role in agricultural activities, the provision of animal's draft power is particularly crucial [21].

Tsetse transmitted animal trypanosomiasis still remains as one of the largest causes of livestock production losses in Ethiopia [9]. The effects of trypanosomiasis is not only the direct losses resulting from mortality, morbidity, infertility of the infected animals and costs of controlling the disease but also due to indirect losses, which include exclusion of livestock and animal power based crop production from the huge fertile tsetse infested areas [21].

It is widespread throughout of the African continent from the southern borders of the Sahara to approximately $20^{\circ}$ south Latitude and is a major factor in holding back the development of these vast areas [22]. It is the most serious veterinary and animal production problem in sub-Saharan Africa and prevents the keeping of ruminants and equines over 10 millions of square kilometers of potentially productive land (which covers one third of the continent). Hence, this study is the road map and contribution to the Pan African Tsetse and Trypanosomiasis Eradication Campaign agenda [23]. It is one of the most significant and costly disease in Ethiopia hindering the effort made for food sufficiency [12].

Currently about 3 million livestock die every year due to tsetse fly transmitted trypanosomiasis to be 10 million $\mathrm{km} 2$. A recent study estimated the direct annual cost of trypanosomiasis to be about 1.34 billion US \$. African livestock producers are administering an estimated 35 million curative and prophylactic treatments annually which costs the producers and the government at least 35 million US\$ [24]. The direct losses from trypanosomiasis in livestock include mortality, morbidity, impaired fertility and the cost of implementing and maintaining tsetse fly and trypanosomiasis control operations. Indirect losses stem from farmers responses to the perceived risk of the disease, including the reduction and in some cases, the exclusion of livestock from tsetse-infested grazing lands and reduced crop production due to insufficient animal draught power.

Trypanosomiasis of domestic livestock covers a great area than of human trypanosomiasis. It has a major importance in cattle and, in some regions, in camels, pigs and other domestic animals. The reduced capacity for work animals is also a very important factor where $80 \%$ of the traction power in African Agriculture is provided by animals. Generally there is a great threat of trypanosomiasis which is a major obstacle to the economic 
development of the African continent and also reasonable for the incalculable toll of human health [12].

Ethiopia has about 14 million heads of cattle which are exposed to the risk of trypanosomiasis. It is not only the loss in meat and milk production of animals recovering from the disease but the great damage caused by the disease is that it has rendered thousands of hectors of land unfit for settlement and cultivation In addition, some drugs are applied to treat the diseased animals, which are costly. Annual report of National Tsetse and Trypanosomiasis Investigation and Control Center indicated that tsetse transmitted animal trypanosomiasis is still remain as one of the largest causes of livestock production losses in Ethiopia [9].

In Gimbi district of western Wollega zone of Oromiya regional state, trypanosomiasis is one of the most important problems impeding agricultural activity and the production potential of livestock population [25]. Therefore, the objective of the present study was to assess the distribution and apparent density of its vectors in the study area.

\section{Materials and Methods}

\section{Study Area}

Across sectional study was conducted from March to May 2014 in three peasant associations (PAs) of Gimbi district (Tole, Jogir and Inango Denbeli), located about $441 \mathrm{~km}$ to the west of Addis Ababa. It is located at $07^{\circ} 02^{\prime} \mathrm{N}$ and $38^{\circ} 28^{\prime} \mathrm{E}$. The area receives an average annual rainfall of $800-1200 \mathrm{~mm}$ and the average annual temperature is $27{ }^{\circ} \mathrm{C}$. The area is covered with a variety of vegetation pattern of cultivated land, bush land, savannah grassland, and patches of dense forests and strips of riverine forests along the riverbanks. The areas have got a number of wild animals, such as African buffaloes, Bush pigs, warthog, bush buck, kudu, hippopotamus, crocodiles, hyena, antelopes and snakes which are claimed to serve as sources of food for the vector of trypanosomes.

\section{Study Population}

The livestock populations that are found in Gimbi district include cattle $(88,784)$, sheep $(34,446)$, goats $(5,306)$, horses $(2)$, mule $(123)$, donkey $(9,448)$ and poultry $(61,702)$. Among these animals, cattle are the dominant species raised in the area [26].

\section{Study Design and sampling techniques}

Gimbi district was selected purposely based on the extent of the existing problems of Trypanosomiasis, the complaints of farmers and the level of medium to high tsetse challenge in the area. A cross-sectional study design was employed and three peasant associations (Tole, Jogir and Inango Denbeli) were selected based on the veterinarian and farmers reports of the trypanosomiasis and tsetse infestation in the district.

The apparent density was determined based on the mean catches of flies in traps deployed and expressed as the number of fly catch per trap per day [27]. This entomological survey was conducted by deploying a total of 45 mono pyramidal baited traps which were the most important to catch riverine species.
The cage and trap were supported externally by poles; the cone is supported internally by a center of pole end [28]. It was deployed just before the sunrise in the morning in different positions (riparian and savannah) that were very suitable areas for tsetse habitats. This helps to assess apparent densities, distributions and species of tsetse flies and other biting flies which are responsible for trypanosomiasis transmission.

All traps were baited with acetone and octenol (1-3-octane) was dispensed from open vials through an approximately, ' 0 'sized hole while cow urine was filled separated in an open bottles into which a quarter of tissue paper was used and deployed at an interval of 200-250 m. All odors were placed on the ground about $30 \mathrm{~cm}$ upwind of the trap. The coordinates of each trap position were recorded with a Global Positioning System (GPS) and found in the range between 1264 to 1837 meters above sea level (Table 1). After $48 \mathrm{hr}$ or 2 days of trap deployment, the cages were collected and captured flies were identified and sexed according to morphological characteristics and counted $[29,30]$.

The tsetse flies were identified to species level and the other biting flies to the genus level. The apparent density elements were the amount of flies collected from the traps deployed, number of the traps deployed and period of deployment in days and it is calculated as the number of flies collected per functional trap per period of deployment in days [27].

\section{Statistical Analysis}

The apparent density of fly population was calculated by dividing the number of flies caught by the number of traps deployed and the number of days of deployment and expressed as fly/trap/day (FTD).

\section{Results}

\section{Entomological survey result}

An entomological survey was conducted and a total of 58 tsetse flies, 26 Stomoxys, 33 Tabanus and 2 Haematopota were caught from the three selected PAs during study period. Out of two major Glossina species collected (G. m. sub. moristans and G. tachnoids); relatively higher numbers of G. tachnoides were caught in riverine than savanna vegetation types. From the total of tsetse flies collected, majority of them (1.5\%) were females in which high number is Glossina tachnoides as compared to G. m. sub. moristans (Table 1).

\section{Separation of tsetse from other blood sucking flies}

Tsetse are crudely similar to other large flies, such as the housefly, but can be distinguished by various characteristics of their anatomy either with the aid of naked eye or with the microscope. The species of tsetse and other biting flies were identified based on morphological characteristics such as size, color, wing venation and proboscis at the genus level. Tsetse folds their wings completely when they are resting so that one wing rests directly on top of the other over their abdomens, Arista of the antenna has branched hairs on its upper surface, they also have a long proboscis, which extends directly forward and is attached by a distinct bulb to the bottom of their heads and 
Table 1: Entomological survey based on peasant associations

\begin{tabular}{|c|c|c|c|c|c|c|c|c|c|c|}
\hline \multirow{2}{*}{$\begin{array}{l}\text { PAs } \\
\text { Tole }\end{array}$} & \multirow{3}{*}{$\begin{array}{l}\text { Longitude } \\
036^{\prime} 05^{\prime} 93 \\
036^{\prime} 96^{\prime} 35\end{array}$} & \multirow{3}{*}{$\begin{array}{l}\text { Latitude } \\
09^{\prime} 05^{\prime} 79 \\
09^{\prime} 06^{\prime} 05\end{array}$} & \multirow{3}{*}{$\begin{array}{c}\text { Altitude } \\
1295 \mathrm{~m}-1349 \mathrm{~m}\end{array}$} & \multirow{3}{*}{\begin{tabular}{|c|}
$\begin{array}{c}\text { No of Traps } \\
\text { deployed }\end{array}$ \\
15 Traps
\end{tabular}} & \multicolumn{2}{|c|}{ Types and species of flies } & \multicolumn{2}{|c|}{ Sex } & \multirow{3}{*}{$\begin{array}{c}\text { Total } \\
-\end{array}$} & \multirow{2}{*}{$\begin{array}{c}\text { Fly/trap/ } \\
\text { day }\end{array}$} \\
\hline & & & & & & & \multirow{2}{*}{$\begin{array}{l}\mathbf{F} \\
-\end{array}$} & \multirow{2}{*}{$\begin{array}{c}\mathbf{M} \\
-\end{array}$} & & \\
\hline & & & & & Tsetse flies & $\begin{array}{l}\text { G. m. sub. } \\
\text { moristans }\end{array}$ & & & & \multirow{5}{*}{0} \\
\hline & & & & & & G. tachnoids & - & - & - & \\
\hline & & & & & & G. pallidipes & - & - & - & \\
\hline & & & & & & G. fusipes & - & - & - & \\
\hline & & & & & & Ground Total & $\mathbf{0}$ & $\mathbf{0}$ & $\mathbf{0}$ & \\
\hline & & & & & \multirow[t]{3}{*}{ Biting Flies } & Stomoxys & 3 & 5 & 8 & \\
\hline & & & & & & Tabanus & 4 & 11 & 15 & \\
\hline & & & & & & Heamatopota & - & - & - & \\
\hline \multirow[t]{8}{*}{ Jogir } & \multirow[t]{8}{*}{$\begin{array}{l}036^{\prime} 01^{\prime} 51 \\
036^{\prime} 02^{\prime} 77\end{array}$} & \multirow[t]{8}{*}{$\begin{array}{l}09^{\prime} 01^{\prime} 21 \\
09^{\prime} 01^{\prime} 78\end{array}$} & \multirow[t]{8}{*}{$1199 m-1312 m$} & \multirow[t]{8}{*}{15 Traps } & \multirow[t]{5}{*}{ Tsetse flies } & $\begin{array}{l}\text { G. m. sub. } \\
\text { moristans }\end{array}$ & 0 & 1 & 1 & \multirow{5}{*}{1.9} \\
\hline & & & & & & G. tachnoids & 45 & 11 & 56 & \\
\hline & & & & & & G. pallidipes & - & - & - & \\
\hline & & & & & & G. fusipes & - & - & - & \\
\hline & & & & & & Ground Total & 45 & 12 & 57 & \\
\hline & & & & & \multirow[t]{3}{*}{ Biting Flies } & Stomoxys & - & 1 & 1 & \\
\hline & & & & & & Tabanus & 3 & 7 & 10 & \\
\hline & & & & & & Heamatopota & - & - & - & \\
\hline \multirow[t]{8}{*}{$\begin{array}{l}\text { Inango } \\
\text { Denbel }\end{array}$} & \multirow[t]{8}{*}{$\begin{array}{l}035^{\prime} 55^{\prime} 06^{\prime} \\
035^{\prime} 56^{\prime} 81\end{array}$} & \multirow[t]{8}{*}{$\begin{array}{l}09^{\prime} 01^{\prime} 16 \\
09^{\prime} 02^{\prime} 71\end{array}$} & \multirow[t]{8}{*}{$1581 \mathrm{~m}-1798 \mathrm{~m}$} & \multirow[t]{8}{*}{15 Traps } & \multirow[t]{5}{*}{ Tsetse flies } & $\begin{array}{l}\text { G. m. sub. } \\
\text { moristans }\end{array}$ & - & 1 & 1 & \multirow{5}{*}{0.033} \\
\hline & & & & & & G.tachnoids & - & - & - & \\
\hline & & & & & & G. pallidipes & - & - & - & \\
\hline & & & & & & G. fusipes & - & - & - & \\
\hline & & & & & & Ground Total & - & 1 & 1 & \\
\hline & & & & & \multirow[t]{3}{*}{ Biting Flies } & Stomoxys & 1 & - & 1 & \\
\hline & & & & & & Tabanus & 3 & 5 & 8 & \\
\hline & & & & & & Heamatopota & - & 2 & 2 & \\
\hline
\end{tabular}

have an hatchet cell on the wings. But, other blood sucking flies (mechanical transmitters) have proboscis which angled at its base and has no bulb, arista has un-branched hairs on its upper surface, they have no hatchet cell on the wing and their wings are held out at an angle of the abdomen at rest.

Also it needs clarification to distinguish tsetse flies among themselves. For instance, Glossina morsitans has a dark ring on the 4 th tarsal segment of the front leg and the dark last two tarsal segments of the hind leg. Glossina pallidipes has the pale 4th tarsal segment of the front leg, the dark last two tarsal segments of the hind leg and the long median scutellar bristles. Glossina fuscipes has the dark color of most of the tarsal segments of the hind leg and it has a very narrow pale area which crosses each abdominal segments. But, in case of Glossina tachinoides there is a dark color of most of the tarsal segments of the hind leg (Figure. 1,2 and 3 )

\section{Result of Entomological survey Based on Peasant Associations}

In tole PA, there were no investigated tsetse flies but there were biting flies such as Tabanus and Stomoxys which were 15 and 18 in numbers, respectively. The absence these flies in the area might be due to the time in which the survey was conducted. In Jogir PA, about one (1) G. m. sub moristans (female) and fifty six (56) G. tachnoides (45 male and 11 females) were investigated. Totally, about fifty seven (57) tsetse flies were recorded this PA. The fly per trap per day in this PA was 1.9. Different biting flies such as Tabanus (10) and Stomoxys (1) were recorded in this 


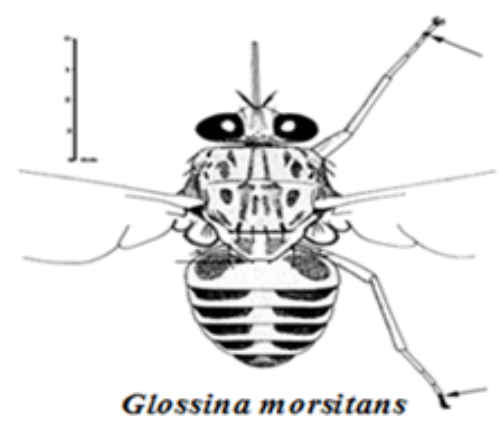

Figure 1

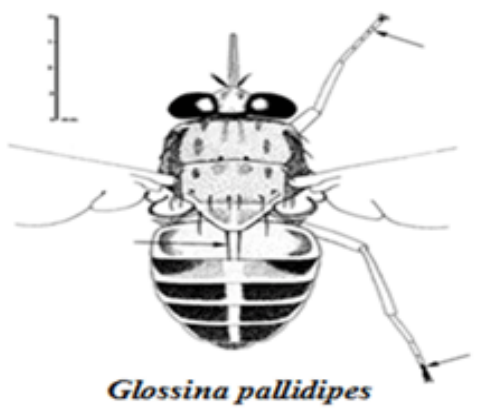

Figure 2

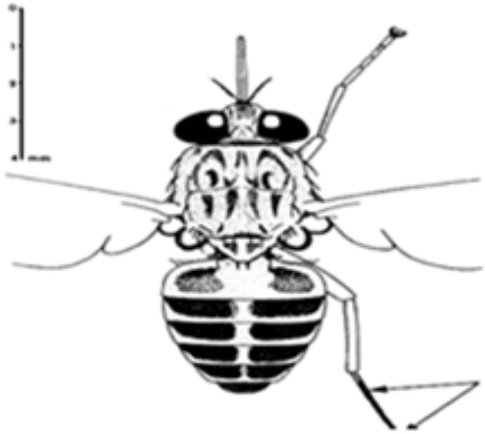

Glossina tachinoides

Figure 3

Figure 1, 2 and 3

PA. In Inango Denbeli PA, only female G. m. sub moristans was investigated and other biting flies like Tabanus (8), Stomoxys (17) and Heamatopota (2) were observed (Table 1).

\section{Apparent densities of tsetse flies Based on sex and vegetation types}

There are different species of tsetse flies based on their vegetation habitats. About 1.9 apparent densities for G. tachnoides and 0.03 densities for G. m. submorsitans were recorded in riverine and savanna vegetation types, respectively.

Sexes of the tsetse flies were done just by observing or palpating the posterior end of the ventral aspect of the abdomen by microscopic lenses as a result male flies were easily identified by enlarged hypophgeum in the posterior ventral part of the abdomen (Table 2).

Table 2: Apparent densities of tsetse fly species $(\mathrm{F} / \mathrm{t} / \mathrm{d})$ in different sex and vegetation types

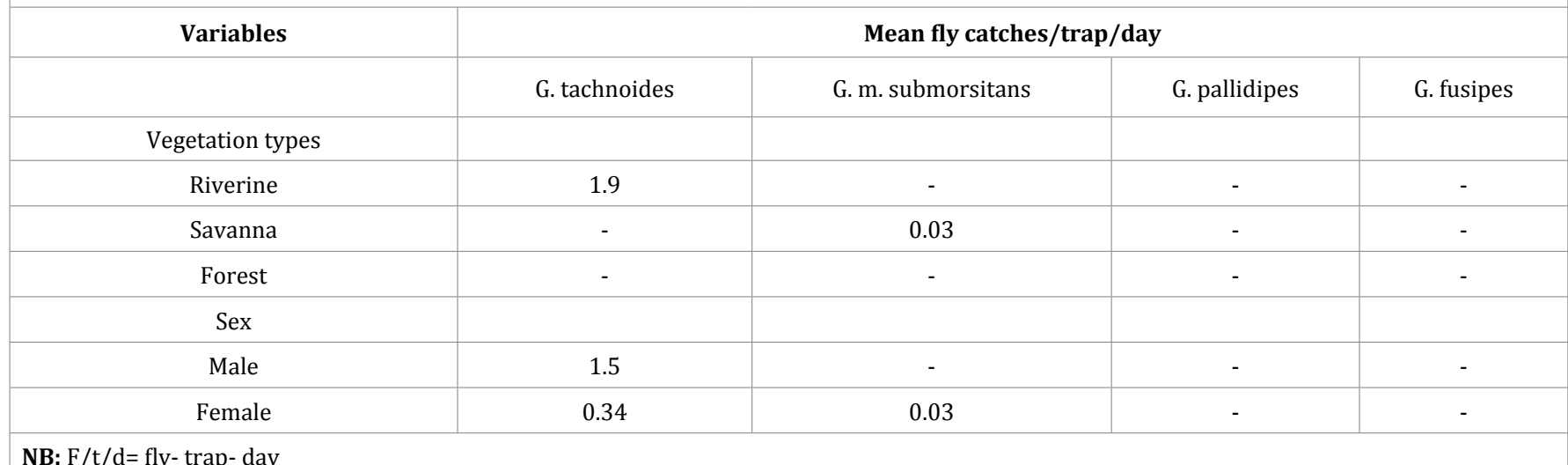




\section{Discussion}

The study was conducted from March to May 2014 in three peasant associations (PAs) of Gimbi district (Tole, Jogir and Inango Denbeli) of western Wollega zone, Oromia regional state to assess the distribution and apparent density of tsetse and other blood sucking flies in the study area. In the present study, an entomological survey was conducted by deploying traps in different positions at approximate intervals of $200-250 \mathrm{~m}$ for 48 hours in watering and grazing points in which the fly and vector are believed to have frequent contacts. Tsetse flies and other flies were collected from selected peasant associations of the study area. The altitude levels, kebelles, numbers of traps, tsetse species caught, other biting flies, days and vegetation types were recorded during the sampling period.

Accordingly a total of 58 tsetse flies (two species of Glossina m. submorsitans and G. tachinoides) with an apparent density of 1.9 flies per trap per day were caught from the three selected PAs during the study period.Additionally, about 61 other blood sucking flies or mechanical transmitters (26 Stomoxys, 33 Tabanus and 2 Haematopota) were caught. Out of two major Glossina species collected (G. m. sub. moristans and G. tachnoids); relatively higher numbers of G. tachnoides were caught in riverine than savanna vegetation types. From the total of tsetse flies collected, majority of them $(1.5 \%)$ were females in which high number is Glossina tachnoides as compared to G. m. sub. moristans (Table 1).

This result was relatively in line with Epidemiology of bovine trypanosomiasis in selected sites of the Southern Rift valley of Ethiopia who reported 1.4 flies per trap per day and higher than Fura 0.3125 flies per trap per day, but less than the study of prevalence of bovine trypanosomiasis and apparent density of Tsetse flies in Sayo Nole District Western Oromia, Ethiopia who reported 13.01 flies per trap per day [31, 32].

A dramatic reduction of mean apparent density of the tsetse flies at Fura village is because of the presence of considerable suppression of flies' population by the use of insecticide impregnated targets and insecticide-treated livestock undertaken in the area [32]. This is also true for Gimbi district, but only chemical method of control of Glossina might not be expected, since a very large number of factors e.g. the climate, the topography and the type of vegetation, affect the outcome. In addition, since the method involves the use of fairly toxic products, every precaution must be taken to avoid ecological disasters and to choose the insecticide to be used more from the point of view of their harmlessness for the environment than for their effectiveness. .

The result of the study indicated that, G. tachnoides and G. m. sub morsitons were tsetse fly species caught in the study area along with other biting flies which was in agreement with Annual Report of National Tsetse and Trypanosomiasis Investigation and Control Center (NTTICC), who reported that, G. pallidipes, G. m. sub-morsitans G. fuscipes and, who reported the presence of G. tachinoides species in Gawo Dale District and Glossina tachnoides, G. m. sub morsitons and G. pallidipes were the tsetse flies species caught along with other biting flies during Epidemiological
Survey of Bovine Trypanosomiasis in Sayo District of Kellem Wollega Zone, Western Ethiopia [33, 34].

Also we have made an effort to conduct an entomological survey based on peasant associations (PAs). In Tole PA, there were biting flies such as Tabanus and Stomoxys which were 15 and 18 in numbers, respectively, but there were no investigated tsetse flies. The absence of these flies in the area might be due to the time in which the survey was conducted. In Jogir PA, about one (1) G. m. sub moristans (female) and fifty seven (57) G tachnoides (45 male and 12 females) were investigated. Totally, about fifty eight (58) tsetse flies were recorded this PA. The fly per trap per day in this PA was 1.9. Different biting flies such as Tabanus (10) and Stomoxys (1) were recorded in this PA. In Inango Denbeli PA, only female G. $\mathrm{m}$. sub moristans was investigated and other biting flies like Tabanus (8), Stomoxys (17) and Heamatopota (2) were observed.

Different apparent densities of tsetse flies were recorded in three villages or PAs (0 in Tole, 1.93 in Jogir and 0.03 in Inango Denbeli). These flies were found in the Didesa and Gelel basin areas (rivers) of selected peasant associations of Gimbi district. Stomoxys $0.33 \mathrm{fly} /$ trap/day, Tabanus $1.1 \mathrm{fly} /$ trap/day and Heamatopota $0.1 \mathrm{fly} /$ trap/day other biting flies were also caught along with tsetse flies. These finding indicate that tsetse and other biting flies were less prevalent in peasant associations adjust to river basin.

Glossina tachinoides was the major species of tsetse fly caught in the study area. Similar findings were reported previously by various researchers that the dominant species of Glossina in the upper Anger and Didessa river valley was G. tachinoides [35].

Regarding the sex composition of the flies, female flies constitute $22 \%$ and this was in agreement with who reported female flies to comprise $70-80 \%$ of the mean population and, was also conducted the study on Prevalence of Bovine Trypanosomiasis and Apparent Density of Tsetse Flies conducted in Sayo Nole District of -Western Oromia, Ethiopia who reported the overall apparent density of tsetse flies trapped was 13.01 flies/trap/day and female tsetse flies were foremost in number and also the present result agrees with the finding of who reported female flies to comprise $32 \%$ of the mean population during the Epidemiological Survey of Bovine Trypanosomiasis in Sayo District of Kellem Wollega Zone, Western Ethiopia [32, 34, 36].

The geographical distributions of the tsetse flies were concentrated in the low land area as climatic conditions are more favorable. Typical habitat patterns found in the study area was favorable for the savannah species (G. m. submorsitans) and riverine species (G. tachnoides). Most of the tsetses were caught in the low land areas and the apparent density decreases as altitude increases. Even though the finding indicated that tsetse and other biting flies were less prevalent in which the finding is supported by earlier 88 works Tsetse and Trypanosomiasis Survey of Ethiopia. Ministry of Overseas Department UK, Altitudinal distribution of tsetse flies in the Fincha valley (western part of Ethiopia), Tsetse Biology and Ecology, Their Role in the Epidemiology 
and Control of Trypanosomiasis in association with the ILRI and Epidemiological Survey of Bovine Trypanosomiasis in Sayo District of Kellem Wollega Zone, Western Ethiopia who indicated that climate, which is largely dependent (influenced) by altitude, has an impact on tsetse population $[8,34,35,37]$.

\section{Conclusion and Recommendations}

The results of apparent tsetse density survey in three kebeles of Gimbi district indicated that, an overall apparent density of 0.97 $\%$ flies per trap per day in which low density of tsetse flies was recorded. During this entomological survey, two species of tsetse flies such as G. morsitons submorsitons and G. tachnoides were identified along with other biting flies. These flies are responsible in transmitting trypanosomosis to the animals in Gimbi district either biologically or mechanically. The current situation may get not worse as the prevention and control of trypanosomosis is practicing in the area and that is limiting the vector and also chemotherapy.

From the obtained result of the study, the following recommendations like enhancement of regular strategic prophylactic treatment and establishment of Veterinary clinic in the control of the parasite, re-establishment of the Veterinary clinic with human force (Vet. workers) and drugs to control the disease, educating the farmers in the area on how to control the vectors of the parasites and the disease properly, expanding an appropriate tsetse control methods (Spot-on and insecticide impregnated targets) to reach tsetse infested area in a sustainable manner, giving attention to reinvasion of the reclaimed area to effective utilizing the control efforts and advising people not to take their cattle to Didessa and the known main tributaries can be additional solution until the control program brings about desired result were forwarded.

1.From the above conclusion of the study, the following recommendations were forwarded:

2.Designing and implementation of control strategies of trypanosomosis focusing integrated approach (vector control and chemotherapy) should be continuing in the studied areas.

3.The farmers in the area should be trained on how to control the vectors of the parasites and the disease properly,

4.Expanding an appropriate tsetse control methods (Spot-on and insecticide impregnated targets) to reach tsetse infested area in a sustainable manner

5.Giving attention to reinvasion of the reclaimed area to effective utilizing the control efforts.

\section{Acknowledgment}

We are grateful to the Bedelle Regional Veterinary Laboratory center and its entire staff member for financial and technical support during this study and giving fed back to the Zone and district.

\section{References}

1. Programme against African Trypanosomosis (PAAT). Comments on the SIT draft position paper by discussion group members of (PAAT ). 1999

2. Erkelens AM, Dwinger RH, Bedane B, Slingenbergh J H W, Wint W, 2000. Selection of Priority Areas for Tsetse Control in Africa; A Decision Tool Using GISin Didessa Valley, Ethiopia, as a Pilot StudyAnimal trypanosomosis: Diagnosis and epidemiology. Results of a FAO/IAEA co-ordinated research programme on the use of immunoassay methods for improved diagnosis of trypanosomosis and monitoring tsetse and trypanosomosis control programmes. 2000:213-236.

3. WaltnerToews D, Kay JK, Neudoerffer C, Gitau T. Perspective changes everything: managing ecosystem from inside out. Frontiers in Ecology and the Environment. 2003;1:23-30.

4. Waltner-Toews D. Ecosystem Sustainability and Health: a Practical Approach. Cambridge University Press, Cambridge, UK. 2004.

5. Keno M. The current situation of tsetse and trypanosomosis in Ethiopia. ISCTRC 28th meeting. MOA and Rural development, veterinary service department, Addis Ababa, Ethiopia. 2005.

6. Christensen NL, Bartuska AM, Brown JH, Carpenter S, Antonio CD, Francis R, et al. The report of the Ecological Society of America committee on the scientific basis for ecosystem management. Ecological Applications. 1996;6(3):665-691.

7. Rogers DJ, Hay SI, Packer MJ. Predicting the distribution of tsetse flies in West Africa using temporal Fourier-processed meteorological satellite data. Annals of Tropical Medicine and Parasitology. 1996;90(3):225-241.

8. Langridge WP. A tsetse and trypanosomosis survey of Ethiopia. Addis Ababa Ethiopia, Ministry of Overseas Development of British and Ministry. 1976.

9. NTTICC. National Tsetse and Trypanosomosis Investigation and Control Center. Report for the Period 7 June 2003- 6th July 2004. Bedelle. 2004:1.

10. NTTICC. National Tsetse and Trypanosomosis Investigation and Control Center. Report for the period 7th July 2001 to 6th July 2002. Bedelle. 2002:3.

11. Donaldson Smith A. Through unknown African countries Edward Arnold, London and John Wilson and Co, Cambridge, U.S.A. 1985.

12. GetachewA. Trypanosomosis in Ethiopia, AAU, FVM, Bishoftu. 2005:18-20.

13. Getachew Abebe JB, Malone, AR, Thompson. Geospatial forecast model for tsetse transmitted animal trypanosomosis in Ethiopia. Ethiopia J. Sci. 2004;27(1):1-8.

14. Leak SGA, W Mulatu, E Authie, AS Perergrine, GJ Rowlands, JCM Trail .Tsetse challenge and its relationship to trypanosomosis prevalence in cattle. Acta Trop. 1993;53(2):121-134

15. Bursell E. Dispersal and concentration of Glossina. In: Mulligan, H.W. (ed.). The African Trypanosomiases. George Allen and Unwin, London. 1970;382-394. 
16. Hargrove JW. A theoretical study of the invasion of cleared areas by tsetse flies (Diptera: Glossinidae). Bulletin of Entomological Research. 2000;90:201-209.

17. Vale GA. Development of baits for tsetse flies (Diptera: Glossinidae) in Zimbabwe. J. Med. Entomol. 1993;30(5):831- 842.

18. Gubler DJ. Resurgent vector-borne diseases as a global health problem. Emerging Infectious Diseases. 1998;4(3):442-450 doi: 10.3201/eid0403.980326

19. Gubler DJ. The global emergence/resurgence of arboviral diseases as public health problems. Archives of Medical Research. 2002; 33(4):330-342.

20. Uilenberge G. A field guide for diagnosis, treatment and prevention of African animal trypanosomosis. Adopted from the original edition by Boyt W.P. FAO, Rome. 1998;43-135.

21. Awoke K Mariam. Study of trypanosomosis and its vectors in Humbo and Merab Woredas; EVA Journal. 2000;4(1):61.

22. WHO. Expert committee in trypanosomosis (First Report) Geneva, 1962:6-18.

23. WHO. The Pan African Tsetse and Trypanosomosis Eradication Campaign (PATTEC). Plan action. 2001.

24. Holmes PH, MC Eisler, Geerts S. Current chemotherapy of animal trypanosomiasis. In: Maudlin I, Holmes P.H. and Miles M.A. (eds) The Trypanosomiases. CABI, UK. 2004:431- 444.

25. Abebe G. Trypanosomosis in Ethiopia. Ethio, J. Bio. Sci, 4. 2005;75121.

26. GLFDRO. Information gained from Gimbi district Livestock and Fisheries Development and Resource Office. 2012.

27. Leak SKA, KA Woume, Collardelle C, Duffera W, Feron A, Mulingo $\mathrm{M}$, et al. Determination of tsetse challenge and its relationship with trypanosomosis prevalence. Livestock production in tsetse infested areas of Africa, ATLN and Nairobi, Kenya. 1987: 43-52.
28. FAO. Food and Agriculture Organization of the United Nations Statistical Database. 2000.

29. Brightwell R, Dransfield RD, Korku CA, Golder TK, Tarimo SA, Mugnai D. A new trap for Glossina pallidipes. Trop. pest manag. 1992; 33: 151-159.

30. Walle R, Shearer D. Veterinary Entomology. Arthropod Ectoparasites of Veterinary importance. Chapman and Hall, London. 1997:1-143.

31. Muturi KS. Epidemiology of bovine trypanosomsis in selected sites of the Southern Rift valley of Ethiopia. FVM, AAU, Ethiopia, MSc Thesis. 2001.

32. Bedaso K. Prevalence of Bovine Trypanosomosis and Apparent Density of Tsetse Flies in Sayonole District Western Oromia, Ethiopia. Veterinary Drug and Animal Feed Administration and Control Authority, Ministry of Agriculture, Addis Ababa, Ethiopia Journal of Veterinary Science \& Technology. 2015;6(5):254-255.

33. NTTICC. National Tsetse and Trypanosomiasis Investigation and Control Centre (NTTICC), Annual Report, Bedelle, Ethiopia. 2009.

34. Siyum Getachew, Tadele Kabeta, Zelalem Abera, Benti Deressa. Epidemiological Survey of Bovine Trypanosomosis in Sayo District of Kellem Wollega Zone, Western Ethiopia. Wollega University, School of Veterinary Medicine, Nekemte, Ethiopia. American-Eurasian Journal of Scientific Research. 2014;9 (3):67-75. doi: 10.5829/idosi. aejsr.2014.9.3.85199

35. Leak SGA. Tsetse Biology and Ecology Their Role in the Epidemiology and Control of Trypanosomosis. CABI publishing in association with the ILRI. 1999;70(4):172-176.

36. Msangi S. Distribution, density and infection rates of tsetse in selected sites of Southern Rift valley of Ethiopia. MSc Thesis, FVM, AAU Ethiopia. 1999.

37. Tikubet, Teferi Gemetchu, Altitudinal distribution of tsetse flies in the Fincha valley (western part of Ethiopia). Insect. Sci. Application. 1984;5(5):389-395. 